American University Washington College of Law

Digital Commons @ American University Washington College of

Law

Articles in Law Reviews \& Other Academic Journals

Scholarship \& Research

1988

Private Information and the Deterrent Effect of Antitrust Damage Remedies

Jonathan Baker

Follow this and additional works at: https://digitalcommons.wcl.american.edu/facsch_lawrev

Part of the Antitrust and Trade Regulation Commons, Contracts Commons, and the Legal Remedies Commons 


\title{
Private Information and the Deterrent Effect of Antitrust Damage Remedies
}

\author{
JONATHAN B. BAKER
}

Dartmouth College

\section{INTRODUCTION}

The private treble damages remedy for antitrust violations allows the victim to collect triple the overcharge from the antitrust violator. This remedy is intended to deter antitrust violations, compensate victims, and prevent the unjust enrichment of lawbreakers. Critics contend, though, that it deters the creation of joint ventures that would produce large social cost savings, and that the haphazard nature of compensation is unfair to victims as a class.

In this article I evaluate systematically the allocative consequences of the set of possible private antitrust damages remedies, including treble damages, with a partial equilibrium model. Both buyer (victim) and seller (violator) are modeled as optimizing actors in a world where the prospect of a successful private antitrust damages action is uncertain. The model recognizes the importance of ancillary social benefits arising from anticompetitive actions. Anticompetitive seller behavior is deterred by the prospect of antitrust dam-

The author is indebted to A. Mitchell Polinsky, Timothy F. Bresnahan, Steven C. Salop, and the Law and Economics Program, Stanford Law School. This paper is a revised version of an earlier work that discusses these issues in more detail. Stephen Salant independently derived some of the results presented here.

Journal of Law, Economics, and Organization vol. 4, no. 2 Fall 1988

(C) 1988 by Yale University. All rights reserved. ISSN $8756-6222$ 
ages, and the prospect of a damage recovery induces buyers to increase purchases from antitrust violators. ${ }^{1}$

The major innovation of this article is in the analysis of antitrust damage remedies when buyer and seller may have private information concerning the likelihood of a successful antitrust recovery (cartel detection and conviction). The model demonstrates that the deterrent effect of antitrust damages depends crucially upon the extent of private information. When the buyer treats his antitrust recovery as a windfall, the polar assumption adopted in previous economic analyses of antitrust damages, damages have some deterrent effect. In the opposite polar case, in which buyer and seller have the same ex ante assessment of the probability of successful antitrust enforcement by buyer against a seller cartel, as would occur if private information were revealed completely by market prices, this article proves a remarkable result: resource allocation under the private antitrust damages system is no different from resource allocation in the absence of antitrust law. Without information differences the private antitrust damage remedy neither deters cartel formation nor gives cartels an incentive to alter output from the monopoly level. The preexisting relationship between buyer and seller allows them to contract around the damage remedy when they anticipate the possibility of harm.

In this article I also show how the efficient private damage remedy varies with the extent of private information. The efficient remedy is the damage rule that leads to efficient resource allocation under decentralized buyer and seller decision making. The efficient remedy charges the violator the net harm to victims when the buyer has no private information and never expects to be successful in an antitrust action against the seller. That well-known result is generalized by deriving the efficient remedy when both parties are allowed to possess private information and when information is revealed through prices.

\section{RESOURCE ALLOCATION UNDER THE PRIVATE DAMAGES REMEDY}

In the absence of antitrust law, sellers in the same industry will coordinate both production and pricing. The model presented in this article assumes that sellers act anticompetitively through a price-fixing cartel. The exploitation of seller market power in other forms could, however, be studied similarly through redefinition of notation. In the discussion below, the seller will

1. The buyer's prelitigation incentive to view an expected damage recovery as a reduction in the effective price charged by a cartel was first suggested in the antitrust context (but not modeled) by William Breit and Kenneth Elzinga (1974: 340 n.30), who termed it a "perverse incentive." William Landes has derived the efficient damage remedy for the case in which victim behavior can be ignored. Michael Block, Frederick Nold, and J. Gregory Sidak have presented an empirical analysis of the deterrent effect of public antitrust enforcement, but do not take into account the behavior of both violator and victim. Economic research on antitrust damages is surveyed by William Breit and Kenneth Elzinga (1985). 
be treated as a single actor who behaves either competitively or cooperatively. The buyer may be thought of as a representative consumer, although most of the results require no more strict an assumption than that individual buyer demand curves aggregate into a downward sloping market demand curve. $^{2}$ In order to focus on the effects of differential buyer and seller information, the model ignores litigation costs and the possibility that parties may choose to settle their dispute before a verdict is reached. ${ }^{3}$

\subsection{Private Antitrust Enforcement}

Under a system of private antitrust enforcement, the buyer can recover damages $\mu M(X, P, C, J)$ from the seller by proving seller collusion. This expression is an arbitrary function, determined by antitrust law, of all variables a court may observe, including equilibrium industry output $(X)$, equilibrium price $(P)$, the cost of producing the given output by firms acting alone $(C)$, and the cost savings achieved through production coordinated among sellers $(J)$. In the model described below, the equilibrium price and both cost variables are functions of output, so the damage remedy can be treated as a function of output alone with no loss of generality, and will be written as $\mu M(X)$.

Under the familiar "treble damages" function, $M(X)$ represents the seller's overcharge of the buyer, and the constant $\mu$ is the multiple three. The damage base $M(X)$ must always be positive, as antitrust law does not force victims to subsidize anticompetitive sellers. The overcharge typically falls as a cartel increases output from the monopoly output toward the efficient level. Hence marginal damages $\mu M^{\prime}$ are likely negative in the range between monopoly and efficient outputs.

Although time does not explicitly appear in the model, two time periods are implicit. In the first, the buyer purchases the seller's output. Later, the buyer may sue the seller under the antitrust laws. ${ }^{4}$ At the time of the purchase, a future antitrust recovery is an uncertain contingency with some probability of occurrence. That probability depends upon both buyer detection of anticompetitive activity and successful judicial enforcement. The function $\theta($ ) represents the buyer's ex ante subjective probability of a future damage recovery (detection and conviction). Similarly, the function $\phi($ ) represents the seller's ex ante subjective probability of future damage payments to the buyer. The buyer and seller are assumed to be risk neutral.

The seller is the most likely candidate to have private information, as he can hide the presence of a cartel from the buyer. Whenever the seller has

2. Welfare comparisons are made using the consumer's surplus, though, implicitly ignoring income effects if the buyer is a consumer.

3. The model also assumes that only overcharged buyers bring private suits.

4. The buyer's damage recovery from the seller is assumed to be adjusted by the appropriate opportunity cost of capital so that neither buyer nor seller expects to gain or suffer from the delay. 
private information concerning his own anticompetitive activities, the buyer will not assess a future damage recovery as more likely than the seller will conjecture. Hence, the discussion below assumes that the buyer's probability assessment is never greater than the seller's $(0 \leqslant \theta \leqslant \phi<1)$.

The buyer's and seller's probability assessments are both endogenous in the model, determined entirely by observable variables. With no loss of generality, they are assumed to vary with output alone: $\phi(X)$ and $\theta(X)$. The endogeneity of each party's probability assessment could arise from the technology by which the cartel's victim detects and convicts the seller of an antitrust violation. If the buyer is willing to spend more resources to investigate seller behavior when the appropriated consumer's surplus is greatest, or if courts are more likely to convict the seller of an antitrust violation when the overcharge is large, then the probability of cartel detection and conviction will rise as the cartel reduces output. ${ }^{5}$ Under this "overt behavior" explanation for endogeneity of the probability of detection and conviction, both the buyer's and the seller's marginal probability assessments will be negative: $\phi^{\prime}(X)<0$ and $\theta^{\prime}(X)<0 .^{6}$

Alternatively, the probability of cartel detection and enforcement may vary with output through each party's ability to learn the other's private information by observing market behavior. ${ }^{7}$ In the present model the only way for the parties to learn each other's private information is by inference through observing changes in the one independent equilibrium variable, either output or price. It is therefore a completely general representation of buyer and seller learning to postulate that both the buyer's and the seller's subjective probability assessments are functions of output.

Under one plausible updating rule for combining this learning with each party's prior probability assessment to generate a posterior probability assessment, each subjective probability estimate will fall as output falls. According to this description of what will be termed the "shared information" model, $\phi^{\prime}(X)>0$ and $\theta^{\prime}(X)>0$. The updating rule assumes that, having observed output $X$, the buyer creates his posterior probability $\theta(X)$ as a linear

5. A variant of this story assumes that cartels become easier to detect as the joint cost savings they achieve increase, because cooperation requires observable changes in the physical production process. According to this view, the seller would have an incentive to alter cooperative production technology in a technically inefficient manner in order to hide the presence of coordinated seller activity. As the model emphasizes the allocative inefficiencies arising from antitrust damages, it ignores this incentive; technical efficiency is assumed throughout.

6. Other cartel detection technologies could lead to non-negative marginal probabilities. For example, if buyers infer the existence of a seller cartel only when they observe an outbreak of competition, the marginal probability of detection might not vary negatively with shifts in seller output.

7. It is well known that private information may be revealed by market behavior. (Grossman and Stiglitz, 1976, 1980; Radner: 108-09). This article does not make explicit the informational structure of private beliefs, the process (Bayesian, for example) by which beliefs are updated, the nature of new information, or the timing of its revelation. The existence of an informational equilibrium is assumed. 
combination of his prior probability estimate and his inference of the seller's probability $\phi(X)$. If output rises, the buyer infers that the seller is trying to reduce damages because the seller's probability estimate is high, and the buyer raises his own probability estimate in response. Similarly, the seller increases his own subjective probability estimate when output rises, through learning that the buyer's estimate is high by observing the buyer's increase in demand. Without imperfect information, that is, excluding the possibility of endogeneity from either "overt behavior" or "shared information," both probabilities will be exogenous constants $\left(\phi^{\prime}=\theta^{\prime}=0\right)$, and the buyer's and seller's probability assessments can differ systematically.

The buyer has an underlying willingness to pay function $R(X)$, derived from preference maximization. ${ }^{8} R(X)$ would be the market (inverse) demand curve in the absence of antitrust. When the buyer is able to collect antitrust damages, he views his expected damage recovery $\theta(X) \mu M(X)$ as a reduction in the effective price he must pay the seller. The expected price to the buyer is less than the market price $P(X)$ by an amount equal to the buyer's expected per unit damage recovery $\theta(X) \mu M(X) / X .^{9}$ The buyer equates this expected price with his underlying true willingness to pay per unit, $R(X)$. Hence the following relation obtains between the market price $P(X)$ and the buyer's underlying preferences $R(X)$ :

$$
P(X)=R(X)+\theta(X) \mu M(X) / X
$$

Seller revenues per unit sold equal the market price $P(X)$. Seller profits, defined in equation (2), are reduced by the seller's expected damage payment to the buyer. The expression $C(X)-J(X)$ represents the seller's production costs, where $J(X)$ represents cost savings on account of coordinated production. $J(X)$ is zero if individual sellers do not coordinate production, or if that production generates no cost savings.

$$
\pi=P(X) X-[C(X)-J(X)]-\phi(X) \mu M(X)
$$

Equation (3) incorporates buyer behavior (1) into the definition of seller profits. The arguments of the functions have been suppressed.

8. The implicit preference function that allows $R(X)$ to depend on the seller's output alone, and not on consumption of other goods or income, is quasi-linear in the seller's output. For a consumer good, this in effect assumes that the income elasticity of demand for $X$ is zero and that consumer's surplus is an exact welfare measure. If $X$ is an intermediate good, the buyer would be interpreted as a downstream firm with derived demand $R(X)$ for the output of an upstream seller.

9. The market demand curve is derived in the usual way from the preference maximization of many buyers, each taking the market price as given and each taking the expected per unit damage recovery as given. Hence in aggregate the buyer treats the expected per unit damage recovery as a constant. The market price is thus the willingness to pay of the marginal buyer, who receives an average amount of damages if buyers as a group successfully challenge the seller cartel in court. 


$$
\pi=R X-(C-J)+(\theta-\phi) \mu M
$$

The equilibrium output under the private antitrust damage remedy, $X^{\prime \prime}$, is implicitly determined by the first-order condition (4), derived by maximizing profits (3) with respect to output.

$$
X^{e} \text { s.t. } R+X R^{\prime}-(C-J)^{\prime}=(\phi-\theta) \mu M^{\prime}+\left(\phi^{\prime}-\theta^{\prime}\right) \mu \mathrm{M}
$$

The seller exploits market power so long as it is profitable to do so. Convexity of the profit function is assumed. ${ }^{10}$ Profits are constrained not to be negative.

The damage remedy forces the seller to balance his desire to maximize pre-antitrust law profits with a desire to minimize expected damage payments; these are the two elements of profits in equation (3). First-order condition (4) shows how that balance is struck. The left-hand expression is the difference between the marginal revenue and marginal cost curves that would obtain in the absence of antitrust. If this expression is negative, equilibrium output will exceed the monopoly output. The two right-hand expressions incorporate different influences of antitrust damages on buyer and seller behavior. The first expression reflects the direct effect of the seller's damage payment to the buyer in raising seller marginal cost: seller marginal cost increases by the seller's expected net marginal damage payment net of the buyer's expected marginal damage recovery. "This term will likely be less than zero, as marginal damages are negative in the range between the monopoly and efficient outputs, and the buyer's probability assessment does not exceed the seller's. Hence the direct effect of antitrust damages will tend to raise seller marginal cost, lead the seller to increase output above the monopoly output, and deter anticompetitive conduct to some extent. The second right-hand expression reflects an indirect influence of antitrust damages on buyer and seller. The buyer and seller recognize that changes in output alter the enforcement probability and thus affect expected damages. The sign of this expression will depend upon the signs and relative sizes of $\phi^{\prime}$ and $\theta^{\prime}$.

The equilibrium output will be compared to three other output levels: monopoly, efficient, and competitive outputs. The monopoly output $X^{m}$, implicitly defined in equation (5), is the equilibrium output in the absence of antitrust law.

$$
X^{m} \text { s.t. } R+X R^{\prime}-(C-J)^{\prime}=0
$$

10. The second order conditions rule out sharply increasing returns to scale under the overcharge damages remedy defined below.

11. The portion of the seller's gross expected marginal damage payment that the buyer anticipates recouping affects the market price through equation (1) without altering expected seller profits, so it does not affect the equilibrium output. 
Without antitrust law both total and marginal damage payments $(\mu M$ and $\left.\mu M^{\prime}\right)$ are zero. Hence equation (5) may be derived by setting the right-hand expression of equation (4) equal to zero.

The efficient output $X^{0}$ is defined in equation (6).

$$
X^{o} \text { s.t. } R=(C-J)^{\prime}
$$

At the efficient output seller achieves all economies of joint production but does not exercise market power. The competitive output $X^{c}$ is defined in equation (7). At the competitive output the seller acts as a price taker but does not coordinate production among firms to achieve cost economies.

$$
X^{c} \text { s.t. } R=C^{\prime}
$$

Figure 1 depicts the relation between the efficient, competitive, and monopoly outputs when marginal cost is rising. The efficient output must always be the largest, but the relative size of the competitive and monopoly outputs

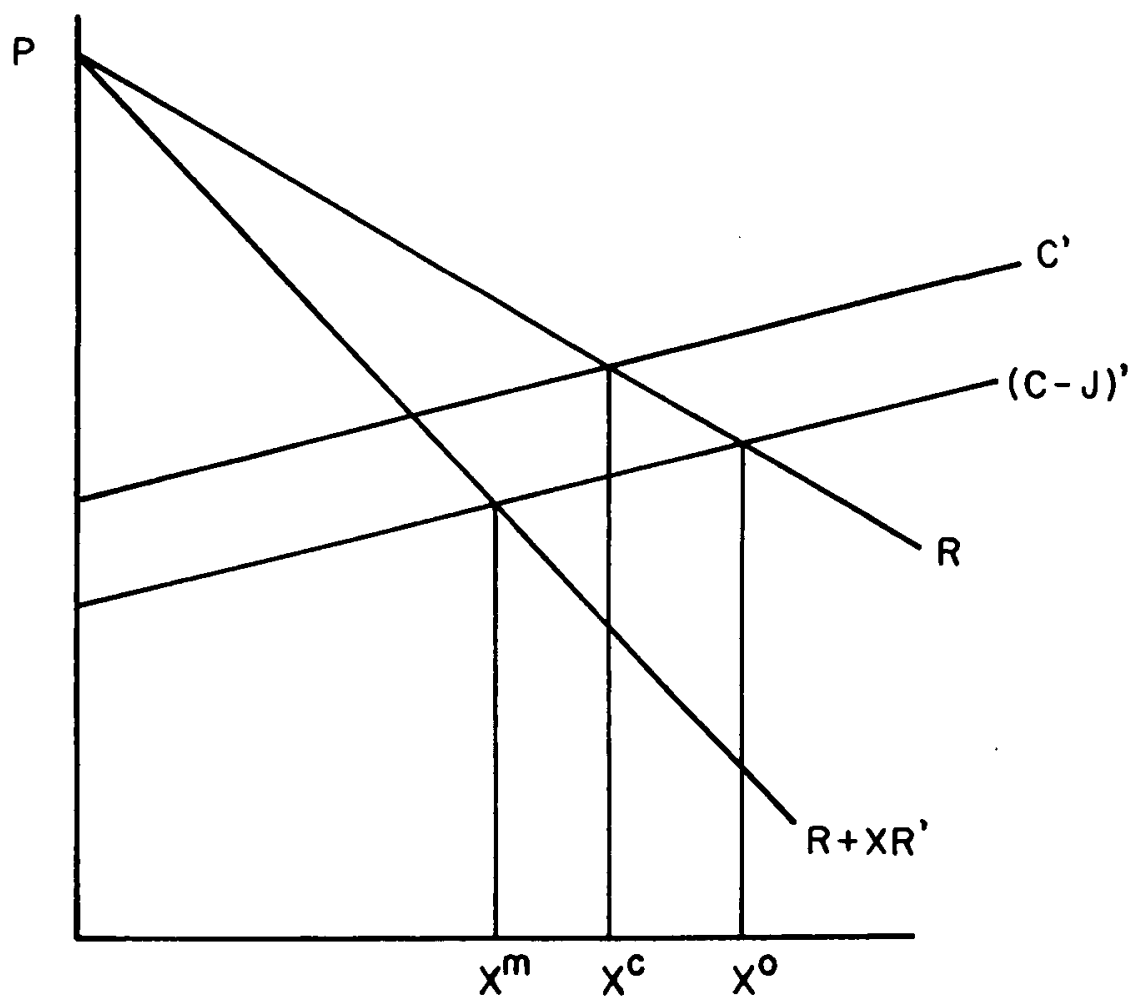

Figure 1. Monopoly, competitive, and efficient outputs when marginal cost is rising. 
depends on the extent of joint cost savings and on the elasticities of demand and supply.

This article highlights the differing effects of two extreme informational assumptions on equilibrium output. At the time the buyer contracts for the seller's product or service, the parties are uncertain about whether the buyer recognizes that the seller is acting anticompetitively and whether the buyer would be successful in a private antitrust action against the seller (because of the difficulties of proof). If the buyer has the same information as the seller about the seller's violation and the buyer's prospects of success in court, then the buyer is termed "informed." If instead the buyer acts as if the seller were not violating the antitrust laws, or if the buyer assigns a probability of zero to the likelihood of a successful damages action, then the buyer is termed "uninformed."12

1. Informed Buyer. The assumption that the buyer is informed restricts both the levels and the derivatives of $\phi(X)$ and $\theta(X)$. When the buyer has identical information as the seller, both will arrive at the same subjective probability point estimate as to the likelihood of successful antitrust enforcement $(\phi=\theta)$. Further, with identical information each party will interpret a change in output the same way $\left(\phi^{\prime}=\theta^{\prime}\right)$.

The informed buyer case could arise in at least two plausible ways. First, if the buyer and seller exchange information through marketplace behavior so that no private information remains, the two parties will assess the probability of seller detection and conviction identically. Further, if the buyer and seller are capable of learning each other's subjective probability assessment, they are capable of learning the function by which that probability is adjusted, so their marginal probability assessments will also be equal.

Alternatively, even if the parties are unable to learn each other's private information through observing market output, it is possible that neither buyer nor seller possesses any private information. Industry participants necessarily share a great deal of knowledge about industry activity, and the buyer and seller will probably hold similar views about the general nature of antitrust enforcement. If they do not learn from each other but possess identical information, they are likely to react identically to output changes in updating their probability assessments.

Under the assumption of an informed buyer, first-order condition (4) is identical to condition (5), which defines the monopoly output. This equivalence means that when buyers are informed, cartels choose the monopoly output regardless of the damage rule. ${ }^{13}$ Further, the profit constraint on seller

12. The intermediate "less informed" buyer case, where buyer and seller's ex ante probability assessments differ but buyer recognizes that there is some prospect of a future damage recovery, is analyzed in an earlier work (Baker).

13. An alternative proof proceeds from the definition (3) of seller profits when a private damage remedy exists. If $\theta=\phi$, then $\pi=R X-(C-J)$, regardless of $M$. Hence seller's 
behavior is never binding, regardless of the damage remedy: when $\phi=\theta$, profits (3) reduce to the non-negative expression $R X-(C-J)$. This result means that sellers exploit all possible opportunities for anticompetitive activity, and no cartels are deterred by being made unprofitable. These important observations are stated as Theorem $1 .{ }^{14}$

Theorem 1. When buyers are informed, all cartels choose the monopoly ouput and no cartels are deterred, regardless of the damage rule.

Three explanations will be provided for the surprising result in Theorem 1. First, the damage rule has no effect on equilibrium output because both buyer and seller base their quantity decisions on the price net of the expected damage award per unit. When buyers have the same information as sellers, both parties discount the observed market price by the identical average value of damages. They in effect see through the expected damage award to condition their behavior on the same net price. Hence they act as if antitrust damages did not exist: the net price equals the monopoly price and the monopoly output is produced and sold. Only if the two parties treat the observed market price as generating different expected net prices will the equilibrium level of output alter from the equilibrium in the absence of antitrust.

The second explanation comes from thinking of the damage remedy as a per unit transfer of $\mu \mathrm{M} / \mathrm{X}$ from seller to buyer, much like a tax on a monopolist later rebated to consumers. ${ }^{15}$ The market price $P(X)$ received by the seller increases by precisely the amount needed to undo the expected transfer. ${ }^{16}$ Both seller and buyer base their market behavior on the expected posttransfer price $R(X)$, which is equated to the monopoly price in the equilibrium. Because the expected post-transfer price is the monopoly price, the resulting equilibrium output equals the monopoly output. Increasing the damage function $\mu M$, as by raising the damage multiple, raises the market price without affecting the expected post-transfer price, expected monopoly profits, or the equilibrium output level.

The final explanation is depicted in figure 2 . In this diagram, $R$ is the demand curve in the absence of antitrust, based on underlying preferences.

profits are unaffected by antitrust damages. By maximizing profits when a damage remedy exists under the assumption that the buyer is informed, the seller is in effect maximizing profits in the absence of antitrust, and he therefore chooses the monopoly output.

14. Another equilibrium is possible in the informed buyer case if the market price $P$ is an arbitrary scalar rather than determined by the demand function $P(X)$. In this implausible situation, the efficient output is the equilibrium regardless of the market price.

15. Although the rate of the per unit transfer $\mu M(X) / X$ varies with the equilibrium output, buyer is a price taker so acts as if the equilibrium per unit transfer $\mu M\left(X^{\bullet}\right) / X^{\bullet}$ is constant.

16. Therefore, contrary to Landes (676), if consumers anticipate recovery for seller's overcharge, this does not eliminate the deadweight loss when seller equally anticipates paying damages. 


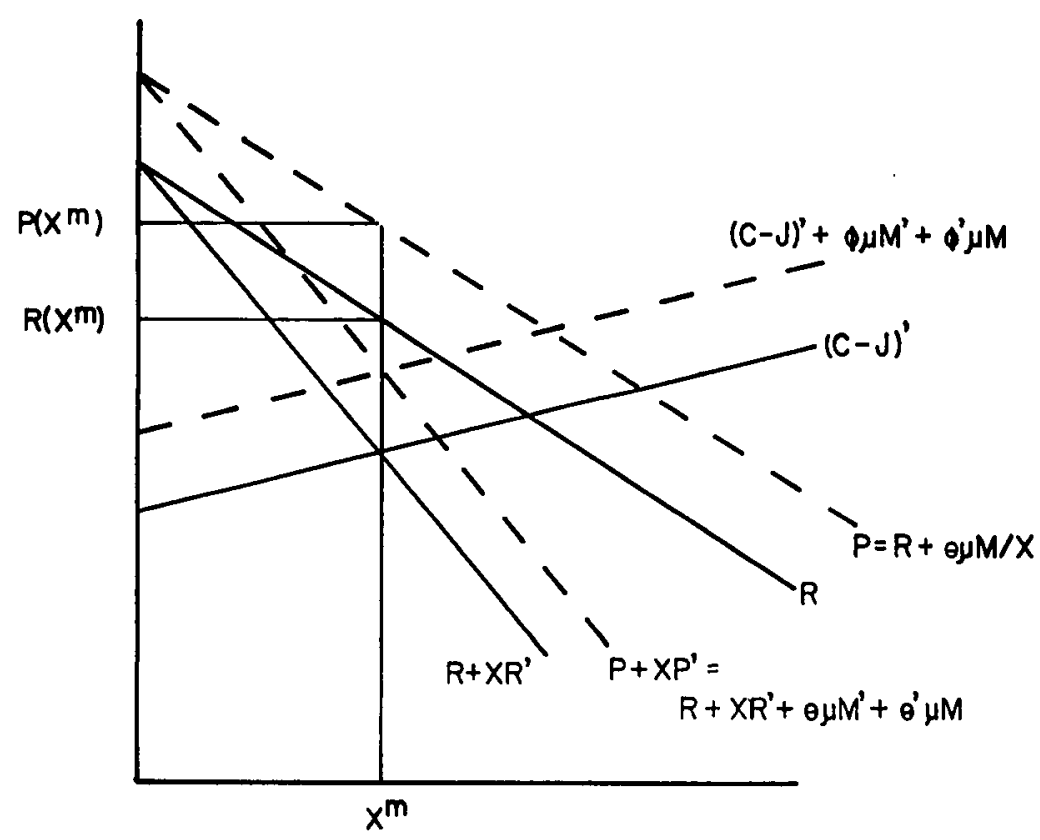

Figure 2. Effect of private antitrust damages when buyers are informed.

The prospect of a private damage recovery shifts the buyer's demand curve to $P$. The seller's marginal revenue curve shifts in response, from $R+X R^{\prime}$ to $P+X P^{\prime}$. The seller's marginal cost curve also rises, however, with the prospect of a future antitrust damage payment, from $(C-J)^{\prime}$ to $(C-J)^{\prime}$ $+\phi \mu M^{\prime}+\phi^{\prime} \mu M$. When the buyer is informed, so $\phi=\theta$ and $\phi^{\prime}=\theta^{\prime}$, the expected damage payment increases the seller's marginal revenue by the same amount as it increases his marginal cost. Thus, a profit-maximizing seller chooses the monopoly output $X^{m}$ regardless of the antitrust damage rule. ${ }^{17}$

Theorem 1 implies that when buyers are informed, the private antitrust damage system is an unattractive mechanism for enforcing competition policy. It deters no cartels, yields no efficiency gains, and in an expected sense fails to generate compensation to victims or to prevent the unjust enrichment of antitrust violators. When the buyer and seller have identical information, the market subverts the best intentions of lawmakers. ${ }^{18}$

17. Price rises in figure 2 by more than the increase in marginal cost, as is plausible in this model. Yet the seller cannot profit by expanding output above the monopoly output, because marginal revenue does not rise by more than the increase in marginal cost.

18. Theorem 1 depends importantly on the often plausible assumption of buyer and seller risk neutrality. If the parties are instead risk averse, however, when recovery is uncertain, a given level of expected antitrust damages is a greater threat to the seller and provides a smaller benefit to the buyer. Risk aversion makes the parties treat the identical level of expected damages 
2. Uninformed Buyer. In the second extreme case, the uninformed buyer case, the buyer treats the damage recovery as a windfall, acting at the time he is purchasing goods as if his subjective probability of detection and conviction were always zero $\left(\theta=\theta^{\prime}=0\right)$. It is sensible to presume that the buyer is uninformed if seller cartels are typically difficult for him to detect when in operation but are susceptible to breaking down in a manner that makes their previous existence obvious to the buyer. ${ }^{19}$ Alternatively, the uninformed buyer case may represent a hypothetical enforcement regime in which there are no private damages actions but the government can collect damages in a civil damages action.

\subsection{Overcharge Remedies (Including Treble Damages)}

One particular damage remedy deserves special attention: the overcharge calculation applied under present antitrust law. The seller pays a multiple $\mu$ of the overcharge, where the overcharge $M$ equals the cartel's price markup times the number of units sold.

In the analysis below, the overcharge will be computed as a markup over the actual (monopolist's) marginal cost $\left((C-J)^{\prime}\right)$, as indicated in equation (8). ${ }^{20}$

$$
M=\left[P-(C-J)^{\prime}\right] X
$$

Under current law the damage multiple $\mu$ is three. ${ }^{21}$

Figure 3 depicts the effect of overcharge damages on the seller's profit

differently, removing the symmetry underlying Theorem 1 and thereby generating some deterrent effect for private damages. This effect of risk aversion will increase as the stakes rise or the probability of detection and conviction falls. Hence under risk aversion, an increased damage multiple is likely to increase the deterrent effect of the private damages remedy.

The result in Theorem 1 also depends on the assumption that litigation costs can be ignored, and that the antitrust case will proceed to a judgment rather than a settlement. If litigation costs are substantial and a party can affect the probability of conviction by increasing expenses on litigation, then litigation expenditures should be treated as an additional decision variable. In this case a seller with market power can purchase increased output reduction ex ante by making credible a commitment of more resources to future litigation, and a buyer can obtain a lower net price ex ante by making credible a commitment of more resources to future litigation. Further, the welfare comparison of alternative damage rules would recognize litigation costs as social costs. Moreover, the possibility of settlement increases the variance of both the damage level and litigation costs, reducing the value of a given expected award to risk averse parties.

19. A similar situation might arise in the present system of mixed public and private antitrust enforcement if the buyer discovers the existence of a seller cartel only when the government brings an enforcement action.

20. An alternative algorithm is also employed in antitrust law for measuring the overcharge. That approach computes the overcharge as a markup over the marginal cost that would have obtained, had the seller been acting as a competitor $\left(C^{\prime}\left(X^{c}\right)\right)$. The two overcharge algorithms are identical if marginal cost is constant and there are no social cost savings from joint production. The results presented in the text do not change markedly if the alternative overcharge calculation is employed (Baker).

21. The multiple equals one in two special cases: when the government is the victim of seller's anticompetitive activity or when the seller is a research and development joint venture. 


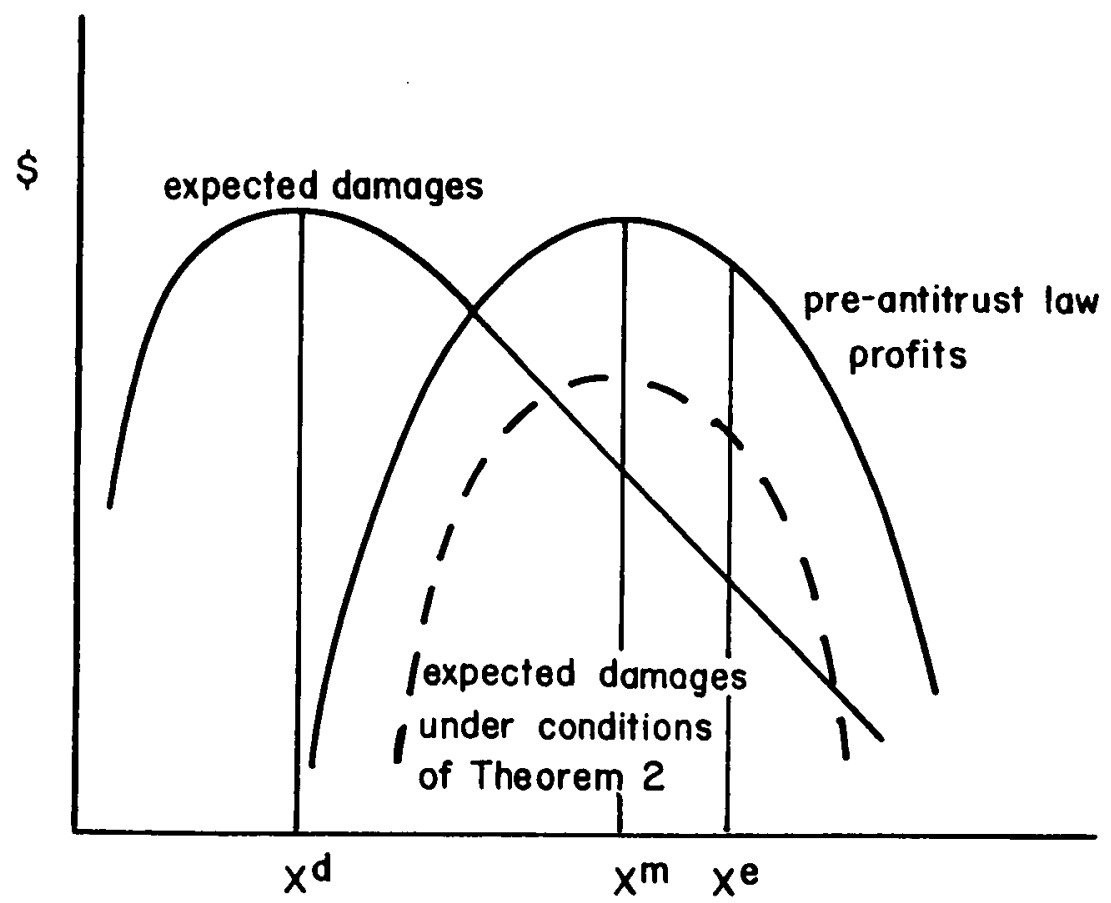

Figure 3. Effect of overcharge damages on seller profits.

maximization. ${ }^{22}$ The pre-antitrust law profits curve is maximized at the monopoly output. Expected overcharge damages are maximized at an output $X^{d}$, not in general equal to the monopoly output. Expected damages likely fall as the cartel increases output above the monopoly output. Net profits under antitrust law, the difference between the curves, are maximized at the equilibrium output $X^{e}$.

1. Profit Constraint.. Seller behavior under overcharge damages is affected significantly by the constraint that profits not be negative. With overcharge damages the effect of the profit constraint can be approximated by the condition that the buyer's and seller's detection probabilities not exceed the inverse of the damage multiple. ${ }^{23}$ If detection probabilities are higher

22. Under overcharge damages, the market demand curve rotates relative to underlying preferences and grows steeper. This can be seen from the reduced form expression for market demand implied by equations (1) and (8): $P=\left[R-\theta \mu(C-J)^{\prime}\right] /(1-\theta \mu)$. The buyer increases his market demand the most when the seller's overcharge is greatest, as then his potential damage recovery is maximized. The rotation occurs at the point where the underlying demand curve equals marginal cost at the efficient output, as that is where market demand $P$ is equated to underlying preferences $\boldsymbol{R}$. 22-24).

23. This is a good approximation when average production costs are roughly constant (Baker: 
than this level, the expected damage function will be uniformly greater than the pre-antitrust law profit function. Then no cartel output will be profitable and cartel formation will be deterred. As a result, with overcharge damages only those cartels with probability assessments less than the inverse of the damage multiple will form. Intuitively, with overcharge damages a high damage multiple makes overt cartels-those with the best chance of detectionunprofitable, deterring their formation. ${ }^{24}$

2. Benchmark Non-Deterrence Conditions.. To understand the effects of overcharge damages on cartel behavior when cartel formation is not deterred by the profit constraint, it is useful to begin by identifying sufficient conditions such that overcharge damages do not cause the cartel to alter output from the monopoly level it would choose in the absence of antitrust. Deterrence of inefficient cartel behavior then would occur entirely through the operation of the profit constraint.

Theorem 2. Assume the buyer is uninformed and the overcharge antitrust damage remedy is employed. A cartel not deterred by the profit constraint will choose the monopoly output if marginal production cost is constant and the seller's probability assessment is exogenous. ${ }^{25}$

This result arises because the overcharge damage remedy function resembles the pre-antitrust law profit function under the assumptions of constant marginal cost, exogenous detection probability, and an uninformed buyer. Theorem 2 holds even though the damage remedy is less than the profit function at all output levels because, as depicted by the dashed curve in figure 3 , the two functions rise and fall in tandem. In consequence, the overcharge damage remedy acts like a tax on economic profit, reducing the seller's profit without altering his profit-maximizing output. ${ }^{26}$

24. This deterrence may be a mixed blessing. Those cartels which remain undeterred by overcharge damages when the buyer is uninformed may well be the worst of all possible cartels in terms of their welfare effects. For example, suppose the horizontal arrangements most easily detected and convincted are those producing social cost savings. This could occur if joint production cost savings require readily observable alterations in the production process, whereas price fixing must be inferred from changes in price alone. When the overcharge damage multiple is high, then, cartels not producing social cost savings are likely to form while beneficial joint ventures are likely to be deterred.

25. Proof: When the buyer is uninformed and overcharge damages are employed, the first order condition is:

$$
\left[R+X R^{\prime}-(C-J)^{\prime}\right](1-\phi \mu)=-\phi \mu X(C-J)^{\prime \prime}+\phi^{\prime} \mu X\left[R-(C-J)^{\prime}\right]
$$

With constant marginal cost and seller's probability assessment exogenous, the right hand expression is zero so the equilibrium occurs at the monopoly output.

26. Under the assumptions of Theorem 2, the reduced form equation for profits under overcharge damages takes the form:

$$
\pi=\left[R-(C-J)^{\prime}\right] X[(1-\phi \mu) /(1-\theta \mu)]+(C-J)^{\prime} X-(C-J) .
$$


3. Factors Promoting Deterrence.. Antitrust damage remedies deter anticompetitive behavior in two ways: by making cartel formation unprofitable and by altering the incentives facing the cartels that do form. When the benchmark conditions of Theorem 2 are present, all deterrence derives from the profit constraint, because any cartel profitable enough to form will select the monopoly output. When cost functions and demand curves vary from the benchmark assumptions, overcharge damages add to the deterrence created by the profit constraint by inducing cartels to increase output above monopoly levels.

The equilibrium output lies above the monopoly level when underlying marginal revenue is less than marginal cost in terms of real resources evaluated at the equilibrium output $\left(\boldsymbol{R}+X \boldsymbol{R}^{\prime}=(C-J)^{\prime}<0\right)$. Hence, for example, the efficient output $X^{0}$ must exceed the monopoly output because equation (6) implies that $R+X R^{\prime}-(C-J)^{\prime}=X R^{\prime}<0$. The ratio $T$, defined in equation (9), forms a natural test statistic measuring the increase in output above the monopoly level induced by the damage remedy. $T$ is defined in terms of preferences and costs in the absence of antitrust, the vantage from which welfare can be assessed.

$$
T=\left[R+X R^{\prime}-(C-J)^{\prime}\right] / X R^{\prime}
$$

The statistic $T$ is an increasing function of output. $T$ will equal zero at the monopoly output, will be negative at outputs below the monopoly output, will rise to unity at the efficient output, and will exceed unity at outputs greater than the efficient output. In figure 4 , when output lies between the monopoly and efficient levels, $T$ is the ratio of segment $b$ to the sum of segments $a$ and $b$.

When the buyer is uninformed and overcharge damages are employed, the test statistic takes the form indicated in equation (10).

$$
\begin{aligned}
T= & {\left[(\theta-\phi) \mu(C-J)^{\prime \prime}\right] /\left[(1-\phi \mu) R^{\prime}\right]+} \\
& {\left.\left[\mathrm{R}-(\mathrm{C}-\mathrm{J})^{\prime}\right] / \mathrm{R}^{\prime}\right] \mu X\left\{\left[\phi^{\prime} /(1-\phi \mu)\right]-\left[\theta^{\prime} /(1-\theta \mu)\right]\right\} }
\end{aligned}
$$

This test statistic is used to derive the effect of several factors upon equilib-

Under the assumption of an uninformed buyer, $\theta=0$. Under the assumption of constant marginal cost, $(C-J)-(C-J)^{\prime} X$ equals fixed costs of production $F$. Hence firm profits may be written:

$$
\pi=\left[R-(C-J)^{\prime}\right] X(1-\phi \mu)-F .
$$

If $\phi$ is an exogenous constant, profits will be maximized when $\left[R-(C-J)^{\prime}\right] X$ is maximized, that is, when the difference between total revenue and total variable cost is maximized. Maximizing this quantity is equivalent to maximizing profits in the absence of antitrust. As with a pure profit tax, the buyer continues to maximize pre-antitrust profit despite the imposition of the damage remedy. 
PRIVATE INFORMATION AND ANTITRUST DAMAGE REMEDIES / 399

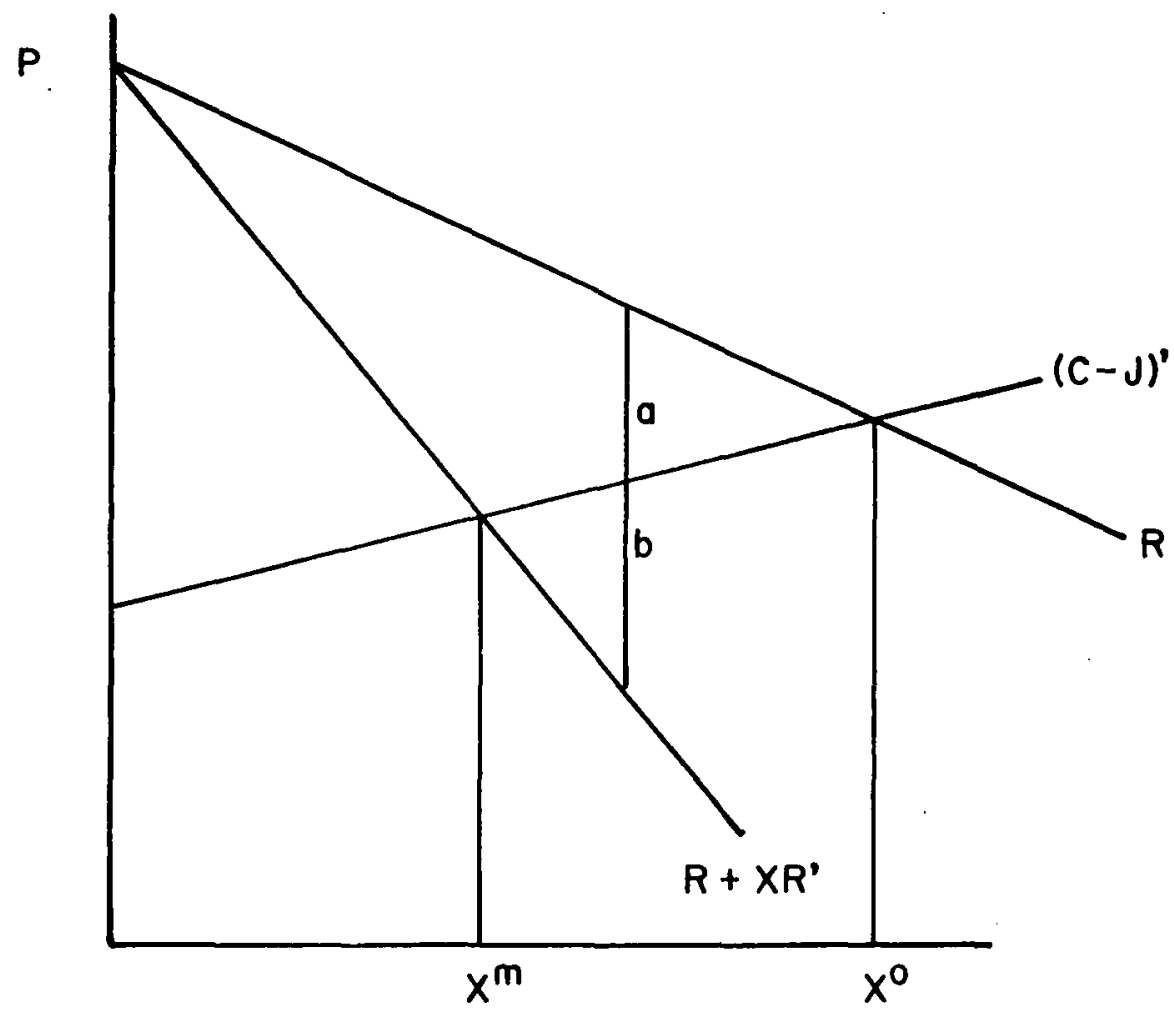

Figure 4. Derivation of the test statistic measuring the effect of private antitrust damages on industry output.

rium output when overcharge damages are employed, including the curvature of marginal cost, the elasticity of underlying demand, and differences between the seller's and buyer's probability assessments. ${ }^{27}$

First, the effect of changing the curvature of marginal cost on output with overcharge damages will be isolated by assuming that the seller's detection probability is exogenous $\left(\phi^{\prime}=0\right)$. Under this assumption, the test statistic has the same sign as $(C-J)^{\prime \prime}$. Decreasing returns to scale will unambiguously increase $T$ above zero, raising cartel output above the monopoly level. This occurs because decreasing returns to scale lowers the output that maximizes overcharge damages, displacing the damage function depicted in figure 3 to the left of the pre-antitrust law profit function and raising the net

27. The effect of social cost savings from coordinated production and the effect of differences between the sensitivity of seller and buyer's probability assessments to changes in output are treated elsewhere (Baker). 
profit maximizing output above the monopoly level. ${ }^{28}$ The seller raises output to avoid the region of highest marginal damages.

Second, increasing the slope of the underlying demand curve (raising $\left|R^{\prime}\right|$ ) heightens the influence of overcharge damages on cartel behavior. A less elastic demand curve raises the seller's expected damage payment in the neighborhood of the monopoly output, thereby inducing him to raise output even farther above the monopoly level. Third, the deterrent effect of overcharge damages increases as the buyer becomes less well informed (holding marginal probabilities constant). The more the buyer's damage recovery is a windfall, the less his market demand increases above underlying demand on account of a prospective antitrust recovery, and the less the seller's expected damage payment will be rebated back to him in the form of an increase in demand.

4. Detrebling Overcharge Damages.. Some suggest that the treble damage multiple is too high and typically propose a reduction to single damages. In the present model, reducing the damage multiple to single damages has two effects. First, the profit constraint is no longer binding, so cartel formation is never deterred. Antitrust law then imposes no bar to the creation of both harmful price-fixing arrangements and beneficial joint ventures. By contrast, under treble damages no cartels will form unless their enforcement probability is less than one-third; all high-detection probability cartels instead choose the competitive output. Therefore the welfare consequences of detrebling relative to the current system depend in part upon whether the high-detection probability cartels that form under single damages but would have been unprofitable under tremble damages choose an output level above or below the competitive output.

Second, detrebling alters the profit-maximizing output of profitable cartels. Thus, the welfare effects of detrebling also depend in part upon the effect of lowering the damage multiple on the equilibrium output of the lowenforcement probability cartels that are profitable to form under both single and treble damages.

The welfare analysis of the effects of detrebling begins with an examination of the behavior of joint ventures and cartels that are allowed to exist under single damages but are deterred by the treble damages remedy. The welfare consequences of allowing the formation of cartels made profitable by detrebling can be assessed by examining whether such cartels produce more than the competitive output, because the seller will act competitively if cartel formation is deterred. If the output of undeterred cartels is less than the competitive output, then society is worse off under detrebling. If instead

28. While decreasing returns to scale also reduces the gap between the monopoly output and the efficient output, the welfare effects of overcharge damages depend upon the relation between the damage-maximizing output and the monopoly output, not upon the relation between the monopoly and the efficient outputs. 
cartel output is greater than the competitive output, welfare is improved by detrebling. ${ }^{29}$

The test statistic $H$, defined in terms of preferences and costs in the absence of antitrust, measures whether cartel output will exceed the competitive output. The notation $C^{\prime}\left(X^{c}\right)=\gamma$ emphasizes that the competitor's marginal cost (that is, marginal cost evaluated at the competitive output) is assumed to be constant, independent of the seller cartel's choice of output.

$$
H=(R-\gamma) / X R^{\prime}=\gamma+\left[(C-J)^{\prime}-\gamma\right] / X R^{\prime}-1
$$

$H$ will be positive if and only if cartel output is greater than the competitive output. ${ }^{30}$ Under the assumption that the seller's and buyer's probability assessments are exogenous, this test statistic takes the following form for overcharge damages:

$$
\begin{aligned}
H= & {\left[(\theta-\phi) \mu X(C-J)^{\prime \prime}+\right.} \\
& \left.(1-\phi \mu)\left((C-J)^{\prime}-\gamma\right)\right] /\left[(1-\phi \mu) X R^{\prime}\right]-1
\end{aligned}
$$

The factors that encourage high-enforcement probability cartels to choose output levels above the competitive level under single damages can be identified from equation (12). High enforcement probability cartels (such that $\phi$ $\geqslant \theta \geqslant 1 / 3$ ) are those which were deterred under treble damages but which single damages make profitable. Assuming that the buyer is less well informed than the seller $(\theta<\phi)$ and that the damages multiple is one, the test statistic will most likely be positive when a cartel faces decreasing returns to scale in production $\left((C-J)^{\prime \prime}\right.$ positive $)$, when demand is elastic $\left(\left|R^{\prime}\right|\right.$ small), and when social cost savings from coordinated production are large $\left((C-J)^{\prime}<\gamma\right)$. The first two conditions limit a cartel's incentive to raise the price above the competitive level, and the last condition requires that joint ventures be socially productive. If most industries satisfy these conditions, it is plausible that treble damages deter socially valuable joint ventures more than they deter socially wasteful cartels.

Detrebling has a second consequence for social welfare. Reducing the damage multiple alters the incentives facing low-enforcement probability cartels, namely those which would form under both single and treble damages. The effect of detrebling on the output of low-enforcement probability cartels can be determined by examining the effect of detrebling on the test statistic $T$ under the assumption that enforcement probabilities are less than $1 / 3$. Under the most plausible assumptions, cartel performance will be worse after

29. The unlikely possibility that a joint venture will create cost savings so large as to cause cartel output to exceed the efficient output is ignored.

30. When cartel output exceeds the competitive output, the value of the marginal unit of output, $R(X)$, will be less than the marginal cost of that unit, $\gamma$. As $R^{\prime}<0, H$ will be positive. 
detrebling because the expected damages function depicted in figure 3 is lowered at all output levels, reducing the net profit-maximizing output $X^{e}$ closer to the monopoly output $X^{m}$. This will be true under overcharge damages if seller production is characterized by decreasing returns to scale and if the buyer is less well informed than seller. ${ }^{31}$

Taking into account the effect of detrebling on both existing and potential cartels, the welfare consequences of detrebling overcharge damages are ambiguous. The change in welfare from detrebling depends importantly upon the distribution of all potential cartels with respect to the ex ante probability of successful enforcement. If most potential cartels are deterred by treble damages because they are easy to detect and convict, the primary welfare effect of detrebling depends upon whether most industries are characterized by elastic demand, decreasing returns to scale, and potentially large cost savings from coordinated activity: if most industries have these characteristics, detrebling will improve welfare by encouraging beneficial joint ventures. If instead most potential cartels are not likely to be detected and convicted, so that they are not deterred by treble damages, detrebling will most likely reduce deterrence and reduce welfare. Thus, if detrebling were the only policy alternative to treble damages, it would be particularly desirable if cartels are unlikely to form (because coordinated behavior is easily detected), if cartel pricing has little effect on welfare (because industry demand is elastic), and if the potential joint cost savings from coordinated production are large. However, the benefits of detrebling in any particular industry and in the economy as a whole cannot be evaluated without empirical evidence on these factors.

\section{EFFICIENT ANTITRUST DAMAGE REMEDIES}

\subsection{Derivation of the Class of Efficient Remedies}

This section derives the class of continuous damage remedies that leads to an efficient resource allocation under private antitrust enforcement. A remedy that fines sellers substantially at all outputs except the competitive output is not continuous and is excluded from consideration. ${ }^{32}$ The analysis assumes risk neutrality of both buyer and seller, but allows for the endogeneity of the detection and conviction probability.

31. When $\theta \leqslant \phi<1 / 3$, so cartels form under both single and treble overcharge damages, $T$ will be larger under treble damages than under singles damages if and only if $\left[(\theta-\phi)(C-J)^{\prime \prime}\right] / R^{\prime}>0$.

32. This remedy requires too much information on the part of the antitrust enforcer to be applied successfully in practice. (Block and Sidak). The assumption that the damage remedy must be continuous also excludes overcharge damages with a very large multiple, although such a regime would create substantial deterrence of anticompetitive activities. The exclusion is necessary because no finite damage multiple will generate complete deterrence if buyers are fully informed. 
This article formalizes and generalizes the analysis found in the literature on efficient antitrust damage remedies. That literature derives the efficient damage remedy for the uninformed buyer case only (Landes: 653-57). ${ }^{33}$ By contrast, the remedy derived below applies when both seller and buyer have private information and when some or all of that information is revealed through market behavior.

The class of continuous damage remedies $\mu M^{*}(X)$ that leads to an efficient allocation of resources consists of those remedies that allow output to satisfy simultaneously the equilibrium condition (4) and the condition defining efficient resources allocation (6). The resulting class of damage remedies takes into account the endogeneity of seller and buyer probability assessments and the social cost savings of joint production.

$$
\mu M^{*} \text { s.t. } X R^{\prime}=(\phi-\theta) \mu M^{\prime}+\left(\phi^{\prime}-\theta^{\prime}\right) \mu M
$$

By integrating equation (13) and imposing the initialization condition that the damage remedy requires no transfer if the seller acts efficiently (that $\left.\mu M\left(X^{0}\right)=0\right)^{34}$ the efficient remedy indicated in equation (14) is derived. The notation $S(X)=\int_{0}^{x} R(t) d t$ is employed.

$$
\mu M^{*}=\left[\left(S^{\circ}-X^{o} R^{o}\right)-(S-X R)\right] /(\phi-\theta)
$$

To interpret the efficient remedy $\mu M^{*}$, it is first necessary to recognize that $R$ is the demand curve in the absence of antitrust, based upon buyer's underlying preferences. $S$ represents underlying aggregate consumer willingness to pay, and $S-X R$ defines the consumer's surplus in the absence of antitrust. Thus, the efficient remedy applies a multiple of $l /(\phi-\theta)$ to a damages base equal to the difference between the consumer's surplus at the efficient and the equilibrium outputs. ${ }^{35}$

The base of the efficient damage remedy, $M^{*}$, consists of the foregone consumer's surplus resulting from the cartel's failure to act competitively. This amount equals the sum of the transfer from consumers to producers and the portion of the allocative efficiency (deadweight) loss that would have gone to consumers. In short, the expression represents the net harm the

33. Landes recognizes that buyer information may alter the efficient remedy derived for the uninformed buyer case, although he does not undertake further analysis (654 n.3, 674-77).

34. This initialization ignores the possibility that sellers behaving competitively could be wrongly convicted of anticompetitive activity. If the normalization were made about another point, such as the competitive output, the efficient remedy would still lead the seller to choose the efficient output. The resulting equilibrium would require buyers to subsidize sellers, however, and firms would earn supranormal profits at the efficient output.

35. The profit constraint does not require separate analysis, as it will always be satisfied at the equilibrium (efficient) output when the efficient remedy is imposed. 
seller's cartel causes others. ${ }^{36}$ The shaded area in figure 5 depicts the damage base defined by equation (14).

Multiplying the net harm to others by the difference between the seller's and buyer's probability assessments makes the expected damage payment equal to the expected net harm the seller causes others. Only the portion of the seller's expected damage payments not returned to the seller through the price increase attributable to a rise in buyer demand forms an expected cost to the seller, so the appropriate multiple equals the inverse of the difference between the seller's and the buyer's probability assessments.

The efficient antitrust damage remedy leads to efficient resource allocation by correcting an externality created by cartel behavior, the allocative efficiency loss. By forcing the seller to bear the entire harm to the buyer from cartel behavior, the efficient damage remedy ensures that the seller inter-

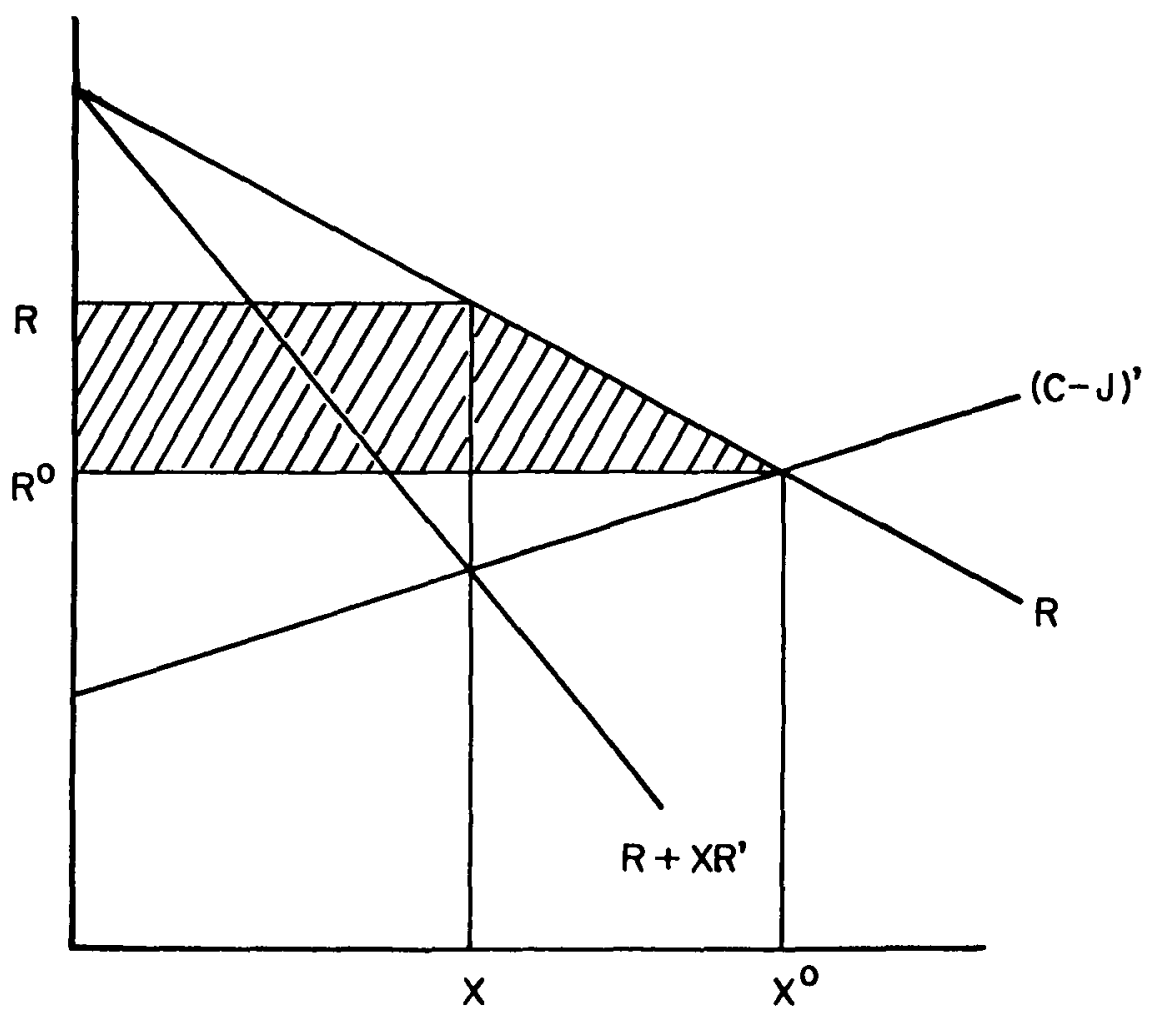

Figure 5. Base of the efficient damage remedy.

36. The "net harm to others" formulation is implicit in Gary Becker's externality analysis of efficient punishment (1968: 191-93). It was first systematically applied to antitrust damages by Landes (656). 
nalizes the entire social cost of his behavior. He is forced to act as a social planner, comparing the total social costs of his behavior with the total social benefits. This remedy is efficient regardless of the endogeneity of buyer and seller probability estimates, ${ }^{37}$ of the curvature of the seller's cost function, or of the extent of social cost savings from joint production among sellers. Theorem 3 summarizes the discussion of the efficient remedy.

Theorem 3. Efficient resources allocation is generated by the following antitrust damage remedy: charge the seller with the foregone consumer's surplus resulting from his restriction of output below the efficient level, multiplied by the inverse of the difference between the seller and buyer's ex ante assessments of the probability of detection and conviction.

If it were possible to apply the efficient damage remedy with precision in every case, no firm would choose to act anticompetitively. All joint ventures creating social cost savings would form, but none would restrict output below the competitive level. Competition policy would be enforced through ex post judicial review of decentralized firm decisions without the tradeoff familiar from overcharge damages between achieving social cost savings from joint production and deterring cartel pricing. ${ }^{38}$

\subsection{IMPLEMENTATION Difficulties}

A system of public antitrust enforcement, awarding government enforcers rather than private plaintiffs the authority to seek damages, is the most practical way to institute the efficient remedy. ${ }^{39}$ By institutionally mandating the uninformed buyer case, four potential implementation difficulties are avoided. First, only under public antitrust enforcement can courts observe

37. It is evident from equation (14), however, that the efficient damage remedy is undefined if the buyer and seller have identical probability assessments. Theorem 1 provides an alternative proof of this assertion.

38. With enough information and computational power, a central planner could always ensure efficient production and pricing ex ante. The informational burden of applying the efficient antitrust damage remedy derived here is significantly less than would be involved in having government enforcers determine and announce efficient production levels ex ante. To apply the efficient decentralized remedy, a court must be able to determine the efficient output ex post if any particular joint venture is challenged. The court need not make an ex ante economy-wide determination of efficient output levels.

39. Breit and Elzinga $(1973 ; 1974 ; 1985)$ have also proposed public enforcement as a way to eliminate victim's prelitigation incentive to increase purchases from antitrust violators, as well as for other reasons. Some of the benefit of public enforcement could instead be obtained by "decoupling" private antitrust damages, for example by charging the violator treble damages while allowing the successful plaintiff (victim) to collect only single damages (with the remaining damage payment given to the U.S. Treasury) (Polinsky). The greater the difference between multiples applied to violator payment and victim recovery, the more decoupling obtains the deterrence benefits of public enforcement, but the more the damage system sacrifices the "private attorney general" incentive embodied in private enforcement. 
the price $R(X)$ which would have obtained in the absence of antitrust law. With the buyer's probability assessment equal to zero, $R$ must equal the observable market price $P$. Second, constraining the buyer's probability assessment to equal zero means that in determining the efficient damage multiple a court need do no more than make a rough unbiased guess as to the seller's ex ante detection probability assessment, based largely upon whether the seller attempted to hide the anticompetitive practice. ${ }^{40}$ Otherwise, a court must estimate the small difference between buyer and seller's probability assessments, a far more difficult task.

Third, constraining the buyer's probability assessment to equal zero rules out the informed buyer case, in which no efficient remedy is possible. Finally, this institutional arrangement rules out the possibility that the buyer's probability assessment exceeds the seller's, and thus the possibility that the buyer will be required to subsidize the seller under the efficient damage remedy.

Three problems apply to implementing the efficient damage remedy in any form. First, a court must determine a substantial segment of both the demand and the supply curves in order to estimate reliably the foregone consumer's surplus. This task may require the use of technical expertise to evaluate econometric evidence. ${ }^{41}$

Second, the efficient remedy implicitly requires that those competitors who do not choose to form a cost-saving joint venture pay a penalty equal to the foregone consumer's surplus resulting from their failure to achieve joint production economies. If instead the efficient damage remedy is enforced with an exception for competitors, output will be indeterminate because firms can maximize profits either by acting efficiently or by acting competitively (Landes: 651 ). ${ }^{42}$

The final difficulty arises if the damage remedy is limited to a public recovery. This limitation reduces the "private attorney general" incentive embodied in private enforcement and limits the avenues for victim selfprotection. Victims could still seek injunctions barring anticompetitive practices, however (and would continue to recoup attorneys' fees when such suits are successful). Further, if the public damages remedy successfully deters anticompetitive behavior, private injunctive relief should never be necessary.

40. The finder of fact must also examine the seller's likely ex ante evaluation of whether the practice would have been illegal under the antitrust law applicable at the time of violation. When antitrust law has changed since the time of the violation, the seller's probability assessment could be low if the practice was arguably legal under the antitrust law enforced at that earlier time, even if the practice was overt.

41. One institutional arrangement circumventing this difficulty would employ the Federal Trade Commission's technical expertise to evaluate econometric evidence by awarding the FTC the exclusive jurisdiction to initiate and adjudicate public damages actions.

42. In order to make the efficient output more profitable than the competitive output, it is necessary to subsidize joint ventures, although the subsidy need not be large. The subsidy must be independent of the output actually chosen by seller in order to leave unaltered the incentives created by efficient damages. 


\section{CONCLUSION}

The private treble damages remedy for antitrust violations has been both condemned and defended for its ability to deter violations and compensate victims. In this article I have shown that under one extreme assumptionthe absence of private information concerning the likelihood of a successful antitrust recovery-neither treble damages nor any private damage remedy can accomplish either goal. So long as antitrust violators possess some private information, however, some private damages remedy (not necessarily treble the overcharge) creates complete deterrence, renders compensation unnecessary, and promotes efficient resource allocation.

An efficient remedy for antitrust violations could be implemented through public enforcement. If instead the policy alternatives are limited to a choice between single and treble damages, as it is sometimes posed, the economic efficiency criterion suggests that detrebling is preferable to the present rule only when cartels are easy to detect and demand is elastic (suggesting that anticompetitive behavior is neither likely to occur nor likely to be damaging) and when the potential joint cost savings from coordinated production are large. These are, however, the opposite assumptions from those animating antitrust law. ${ }^{43}$

\section{REFERENCES}

Baker, Jonathan. 1985. "The Effect of Antitrust Damage Remedies on Resource Allocation," Working Paper No. 22, Law and Economics Program, Stanford Law School.

Becker, Gary. 1968. "Crime and Punishment: An Economic Approach," 76 Journal of Political Economy 169.

Block, Michael, and J. Gregory Sidak. 1980. "The Costs of Antitrust Deterrence: Why Not Hang a Price Fixer Now and Then?" 68 Georgetown Law Review 1131.

Block, Michael, Frederick Nold, and J. Gregory Sidak. 1981. "The Deterrent Effect of Antitrust Enforcement," 89 Journal of Political Economy 429.

Breit, William, and Kenneth Elzinga. 1973. "Antitrust Penalties and Attitudes toward Risk: An Economic Analysis," 86 Harvard Law Review 693.

- 1974. "Antitrust Enforcement and Economic Efficiency: The Uneasy Case for Treble Damages," 17 Journal of Law and Economics 329.

- 1985. "Private Antitrust Enforcement: The New Learning," 28 Journal of Law and Economics 405.

Easterbrook, Frank. 1985. "Detrebling Antitrust Damages," 28 Journal of Law and Economics 445.

43. The Sherman and Clayton Acts are predicated on the view that firms would collude absent governmental prohibition, and that competitive enterprise rather than interfirm planning is the primary source of new products and cost-saving innovations. 
408 / JOURNAL OF LAW, ECONOMICS, AND ORGANIZATION IV:2, 1988

Grossman, Sanford, and Joseph Stiglitz. 1976. "Information and Competitive Price Systems," 66 American Economic Review 246.

- 1980. "On the Impossibility of Informationally Efficient Markets," 70 American Economic Review 393.

Landes, William. 1983. "Optimal Sanctions for Antitrust Violations," 50 University of Chicago Law Review 652.

Polinsky, A. Mitchell. 1988. "Detrebling versus Decoupling Antitrust Damages: Lessons from the Theory of Enforcement," in L. White, ed., Private Antitrust Litigation: New Evidence, New Learning. Cambridge: MIT Press.

Radner, Roy. 1982. "The Role of Private Information in Markets and Other Organizations," in W. Hildenbrand, ed., Advances in Economic Theory. Cambridge: Cambridge University Press.

Salant, Stephen. 1987. "Treble Damage Awards in Private Litigation for Price Fixing," 95 Journal of Political Economy 1326.

Werden, Gregory, and Marilyn Simon. 1986. "An Economic Assessment of the Administration's Detrebling Proposal," 31 Antitrust Bulletin 935. 